\title{
Sexual and Gender Minority Issues Across NCCN Guidelines: Results From a National Survey
}

\author{
Janella Hudson, $\mathrm{PhD}^{\mathrm{a}}$; Matthew B. Schabath, PhD, MPH ${ }^{\mathrm{b}, \mathrm{d}}$; Julian Sanchez, MD ${ }^{\mathrm{c}, \mathrm{e}}$; Steven Sutton, $\mathrm{PhD}^{\mathrm{f}}$; \\ Vani N. Simmons, PhD ${ }^{\mathrm{a}, \mathrm{c}, \mathrm{d}}$; Susan T. Vadaparampil, PhD, MPH ${ }^{\mathrm{a}, \mathrm{c}}$; Peter A. Kanetsky, PhD ${ }^{\mathrm{b}, \mathrm{c}}$; and \\ Gwendolyn P. Quinn, PhD ${ }^{\mathrm{a}, \mathrm{c}}$
}

\begin{abstract}
Background: The lesbian, gay, bisexual, transgender, queer/questioning (LGBTQ) population is at higher risk for multiple types of cancers compared with the heterosexual population. Expert NCCN panels lead the nation in establishing clinical practice guidelines addressing cancer prevention, early detection, and treatment of cancer sites and populations. Given the emergence of new data identifying cancer disparities in the LGBTQ population, this study examined the inclusion of medical and/or psychosocial criteria unique to LGBTQ within NCCN Guidelines. Methods: Data were collected for 32 of the 50 NCCN Guidelines. Results: NCCN panel members reported that neither sexual orientation (84\%) nor gender identity (94\%) were relevant to the focus of their guidelines; $77 \%$ responded that their panels currently do not address LGBTQ issues, with no plans to address them in the future. Conclusions: Greater consideration should be given to the needs of LGBTQ patients across the cancer care continuum. Given that research concerning LGBTQ and cancer is in its infancy, additional empirical and evidence-based data are needed to bolster further integration of LGBTQ-specific criteria into clinical care guidelines.
\end{abstract}

J Natl Compr Canc Netw 2017;15(11):1379-1382 doi: 10.6004ljncen.2017.0169

\section{Background}

The lesbian, gay, bisexual, transgender, queer/questioning (LGBTQ) population, also known as sexual and gender minorities (SGMs), has a higher risk for multiple types of cancers compared with heterosexual and cisgender populations, which is in part attributed to an elevated prevalence of risk behaviors and factors among SGM individuals. ${ }^{1}$ For example, higher rates of human papillomavirus (HPV) in the SGM population contribute to an increased incidence of anal cancer among men who have sex with men (MSM) compared with heterosexual men, ${ }^{2}$ and higher rates of cervical cancer risk factors and behaviors in lesbian women compared with heterosexual women. ${ }^{3}$ There is speculation that higher smoking rates in the SGM community may lead

From the Departments of ${ }^{a}$ Health Outcomes and Behavior and ${ }^{b} \mathrm{Cancer}$ Epidemiology, Moffitt Cancer Center; ' Oncologic Science, Morsani College of Medicine, University of South Florida; Departments of ${ }^{\mathrm{d}}$ Thoracic Oncology, eGastrointestinal Oncology, and 'Biostatistics and Bioinformatics, Moffitt Cancer Center, Tampa, Florida.

Submitted September 21, 2016; accepted for publication January 13, 2017. The authors have disclosed that they have no financial interests, arrangements, affiliations, or commercial interests with the manufacturers of any products discussed in this article or their competitors. to an elevated risk of tobacco-related diseases, such as lung cancer, although there are not yet sufficient data on rates of lung cancer among SGMs. ${ }^{4}$ Collection of sexual orientation and gender identity (SOGI) data is currently not standard, and these data are not included in SEER or other national data sets. Thus, SGM populations have not been followed over time to determine the rates of emergence of new cancer cases, and therefore these and other areas need immediate and careful monitoring. SGMs are less likely to seek cancer screening $^{5}$; face multiple structural, cognitive, and social barriers that decrease the likelihood of screening ${ }^{5-7}$; and are more likely to be economically disadvantaged and underinsured, to underutilize healthcare ${ }^{8}$; and to have poorer cancer-related outcomes. ${ }^{1}$

This study was funded by a Miles for Moffitt Milestone Award (principal investigators: G.P.Q. and M.B.S.) and an NIH R25T training grant (R25CA090314). This work was also supported in part by a Cancer Center Support Grant at the H. Lee Moffitt Cancer Center \& Research Institute (grant number P30-CA76292).

Correspondence: Gwendolyn P. Quinn, PhD, Moffitt Cancer Center, 12902 Magnolia Drive, MRC-CANCONT, Tampa, FL 33612.

E-mail: gwen.quinn@moffitt.org 
Hudson et al

Despite the impact cancer has on the SGM population, a previous study found that most surveyed oncologists lacked knowledge regarding SGM health-related issues and did not inquire about patients' SOGI. ${ }^{9}$ The NCCN multidisciplinary expert panels lead the nation in establishing clinical practice guidelines addressing cancer prevention, early detection, and treatment of cancer sites and populations. ${ }^{10}$ Given the emerging body of research identifying cancer disparities in the SGM population, we conducted a national survey of the NCCN Guidelines panels to assess whether medical and psychosocial issues unique to SGM populations are addressed or will be addressed in the future.

\section{Methods}

Study approval was obtained from Chesapeake Institutional Review Board (Columbia, MD) and a Waiver of Documentation of Consent was granted. We contacted a panel member from each of the NCCN panels $(n=50)$, and they were e-mailed an invitation to participate in the study. Surveys were administered from February through June 2016. A link embedded within the e-mail routed participants to a short Web-based survey (Figure 1) that assessed each panel's current practices and/or future plans for addressing medical and psychological issues relevant to LGBTQ individuals, including the relevance of patients' SOGI to the focus of the guideline (Table 1). Published guidelines for all 50 panels were independently reviewed by 2 members of the research staff to assess the presence of any content specific to

- What is the name of the NCCN Guidelines Panel with which you
are affiliated?
- Do the clinical practice guidelines developed by your panel
currently address lesbian, gay, bisexual, transgender, queer/
questioning (LGBTQ) medical issues?
- Does your panel currently address any LGBTQ psychosocial issues?
- Are there any plans to address LGBTQ issues in the future?
- Is sexual orientation a relevant demographic for the focus of your
panel?
Is gender identity a relevant demographic for the focus of your
panel?

Figure 1. NCCN Panel Member survey.

SGM populations. Survey responses were reported using descriptive statistics and were aggregated by NCCN Guidelines and Clinical Resources groupings (available at NCCN.org) to maintain anonymity.

\section{Results}

Of the 31 responses, $87 \%$ of NCCN panel members self-reported sexual orientation was not relevant to the focus of their guidelines and $90 \%$ reported gender identity was not relevant. Nine panel members reported that their guidelines did address LGBTQ medical or psychosocial issues. Conversely, $87 \%$ of NCCN panel members responded that their guidelines currently did not address LGBTQ medical or psychosocial issues, with no plans to do so in the future; $10 \%$ of panel members noted that although their respective panels did not presently address LGBTQ medical and psychosocial issues, they planned to do so in the future. A review of each re-

\begin{tabular}{|c|c|c|c|c|c|c|c|c|c|}
\hline \multirow[b]{2}{*}{$\begin{array}{l}\text { NCCN Guidelines } \\
\text { Panel Grouping }\end{array}$} & \multicolumn{3}{|c|}{$\begin{array}{l}\text { Do the Clinical Practice Guidelines } \\
\text { Developed by Your Panel Currently } \\
\text { Address LGBTQ Medical Issues? }\end{array}$} & \multicolumn{2}{|c|}{$\begin{array}{l}\text { Do the Clinical } \\
\text { Practice Guidelines } \\
\text { Developed by Your } \\
\text { Panel Currently } \\
\text { Address LGBTQ } \\
\text { Psychosocial Issues? }\end{array}$} & \multicolumn{2}{|c|}{$\begin{array}{l}\text { Is Sexual } \\
\text { Orientation } \\
\text { a Relevant } \\
\text { Demographic } \\
\text { for the Focus of } \\
\text { Your Panel? }\end{array}$} & \multicolumn{2}{|c|}{$\begin{array}{l}\text { Is Gender } \\
\text { Identity a } \\
\text { Relevant } \\
\text { Demographic } \\
\text { for the Focus of } \\
\text { Your Panel? }\end{array}$} \\
\hline & Yes & $\begin{array}{l}\text { No, But Plan } \\
\text { on Addressing } \\
\text { Them in the } \\
\text { Future }\end{array}$ & $\begin{array}{l}\text { No, and Do } \\
\text { Not Intend on } \\
\text { Addressing Them } \\
\text { in the Future }\end{array}$ & Yes & No & Yes & No & Yes & No \\
\hline Cancer by site & 4 & 0 & 14 & 3 & 15 & 2 & 16 & 1 & 17 \\
\hline $\begin{array}{l}\text { Detection, } \\
\text { Prevention, } \\
\text { \& Risk Reduction }\end{array}$ & 0 & 0 & 5 & 0 & 5 & 0 & 5 & 0 & 5 \\
\hline $\begin{array}{l}\text { Supportive Care \& } \\
\text { Age-Related }\end{array}$ & 1 & 3 & 4 & 1 & 7 & 2 & 6 & 2 & 6 \\
\hline
\end{tabular}

aNCCN panel groupings were based on NCCN Clinical Practice Guidelines in Oncology groupings on NCCN.org. 
sponding panels' actual guidelines showed only the NCCN Guidelines for Anal Carcinoma had specific language pertaining to SGM patients. ${ }^{10}$

\section{Discussion/Implications}

Results from our survey demonstrate that integration of SGM-specific issues has not yet reached NCCN panels, perhaps because SGM cancer research is still emerging. Although the majority of respondents indicated that their panels did not address LGBTQ medical and psychosocial issues, with no plans to address them in the future, there were promising exceptions. Similarly, several panel members acknowledged the importance of SOGI to the focus of their panels. These data represent an auspicious start to the creation of policy addressing the unique needs of SGMs across the cancer continuum.

Direct applicability of SGM-related issues may be more readily apparent to panel members depending on the specialty, especially for panels associated with cancer sites for which evidence-based research has demonstrated an SGM-related disparity. For example, the NCCN Guidelines for Anal Carcinoma addresses the higher incidence of anal cancer among MSM and reiterates the Advisory Committee on Immunization Practices' recommendation for HPV vaccination in this population. ${ }^{10}$

It can be argued, however, that consideration of SGM issues has relevance across all NCCN panels and represents best practice in patient care. Indeed, knowledge of patients' SOGI is a relevant factor when identifying risk factors for effective cancer primary, secondary, and tertiary prevention. SGM individuals face unique challenges throughout the course of the cancer care continuum, particularly related to sexual functioning, social support, and access to healthcare. Providers should not assume heteronormativity when interacting with patients; they should actively cultivate an environment that encourages disclosure of SOGI and recognize that SGMs have unique medical needs. ${ }^{11-13}$ Consideration of the unique medical and psychosocial needs of SGM populations should be routinely integrated into clinical practice guidelines in the oncology care setting. Establishing standardized guidelines to improve providers' knowledge about cancer risk in the SGM population will likely improve quality of care for SGM individuals.
Review of the clinical practice guidelines for all responding panels revealed that only the NCCN Guidelines for Anal Carcinoma contained language specifically addressing the unique needs of the SGM population. The NCCN Guidelines for Distress Management and Survivorship did contain vague references to sexuality that were not referenced in the context of SGM-related health. Further research is needed to understand how panels reporting consideration of SGM health-related issues interpret this, because it was not apparent from their guidelines that SGM issues were addressed. Nonresponses from key NCCN panels is a limitation in this study, particularly among panels representing sites with cancer disparities in SGM populations, including prostate and head and neck cancers.

\section{Conclusions}

The results from our national survey demonstrated that NCCN Guidelines Panels are not addressing an emerging, underserved population. The landscape of SGM health is evolving as research and medical fields reveal the unique health needs and disparities

\begin{tabular}{|l|}
\hline Sexual Orientation: \\
Do you think of yourself as: \\
$\square$ Straight or heterosexual \\
$\square$ Lesbian, gay, or homosexual \\
Bisexual \\
$\square$ Something else \\
$\square$ Don't know \\
Gender Identity: \\
Do you think of yourself as: \\
$\square$ Male \\
$\square$ Female \\
$\square$ Female-to-male/Transgender male/Trans man \\
$\square$ Male-to-female/Transgender female/Trans woman \\
$\square$ Genderqueer, neither exclusively male nor female \\
$\square$ Additional gender category/(or other), please \\
specify:_- \\
$\square$ Something else \\
What sex were you assigned at birth on your original birth \\
certificate? (Check one): \\
$\square$ Male \\
Female \\
$\square$ Decline to Answer
\end{tabular}

Figure 2. Recommended data collection of sexual orientation and gender identity in electronic medical records. 
Hudson et al

of this population. Even as new research helps to shape the burgeoning research agenda, much is still unknown about the prevalence, risk, mortality, and quality of life for SGM individuals with cancer. All panels should consider collecting proper SOGI data so that cancer-related issues (eg, incidence, physical, quality of life, outcomes) of this underrepresented population can be assessed and used to modify guidelines in the future. It is also suggested that the panels perform periodic literature reviews on SOGI studies related to their disease site to ensure they are up-todate on the current status of SGMs relative to the panel disease site. The National LGBT Health Education Center, part of The Fenway Institute, ${ }^{14}$ recommends means for collecting SOGI data in electronic medical records (Figure 2). Overall, NCCN Guidelines should reflect greater awareness of the medical and psychosocial needs of SGM individuals.

\section{References}

1. Quinn GP, Sanchez JA, Sutton SK, et al. Cancer and lesbian, gay, bisexual, transgender/transsexual, and queer/questioning (LGBTQ) populations. CA Cancer J Clin 2015;65:384-400.

2. Machalek DA, Poynten M, Jin F, et al. Anal human papillomavirus infection and associated neoplastic lesions in men who have sex with men: a systematic review and meta-analysis. Lancet Oncol 2012;13:487-500.

3. Waterman L, Voss J. HPV, cervical cancer risks, and barriers to care for lesbian women. Nurse Pract 2015;40:46-53.

4. Rath JM, Villanti AC, Rubenstein RA, Vallone DM. Tobacco use by sexual identity among young adults in the United States. Nicotine Tob Res 2013;15:1822-1831.

5. Graham R, Berkowitz B, Blum R, et al. The health of lesbian, gay, bisexual, and transgender people: building a foundation for better understanding. Washington, DC: Institute of Medicine; 2011.

6. Buchmueller T, Carpenter CS. Disparities in health insurance coverage, access, and outcomes for individuals in same-sex versus different-sex relationships, 2000-2007. Am J Public Health 2010;100:489-495.

7. Kamen CS, Smith-Stoner M, Heckler CE, et al. Social support, self-rated health, and lesbian, gay, bisexual, and transgender identity disclosure to cancer care providers. Oncol Nurs Forum 2015;42:44-51.

8. Fredriksen-Goldsen KI, Hoy-Ellis CP, Brown M. Addressing behavioral cancer risks from a LGBT health equity perspective. In: Boehmer U, Elk

R, eds. Cancer and the LGBT Community. Cham, Switzerland: Springer 2015:37-62

9. Shetty G, Sanchez JA, Lancaster JM, et al. Oncology healthcare providers' knowledge, attitudes, and practice behaviors regarding LGBT health. Patient Educ Couns 2016;99:1676-1684.

10. Benson AB III, Venook AP, Cederquist L, et al. NCCN Clinical Practice Guidelines in Oncology: Anal Carcinoma, Version 2.2017. Accessed April 21, 2017. To view the most recent version of these guidelines, visit NCCN.org.

11. American Academy of Family Physicians. Recommended curriculum guidelines for family medicine residents: lesbian, gay, bisexual, transgender health. Available at: http://www.aafp.org/dam/AAFP/documents/ medical_education_residency/program_directors/Reprint289D_LGBT. pdf. Accessed August 31, 2016.

12. Margolies L. The psychosocial needs of lesbian, gay, bisexual, or transgender patients with cancer. Clin J Oncol Nurs 2014;18:462-464.

13. Oncology Nursing Society. ONS endorses the American Academy of Nursing policy brief on support for the rights of LGBT individuals who are hospitalized. Available at: https://www.ons.org/newsroom/news/onsendorses-american-academy-nursing-statement. Accessed August 31,2016.

14. Bradford J, Cahill S, Grasso C, Makadon H. Policy focus: how to gather data on sexual orientation and gender identity in clinical settings. Available at: http://thefenwayinstitute.org/documents/Policy_Brief_HowtoGather... v3_01.09.12.pdf. Accessed August 31, 2016. 